\title{
Objectives of Soil Tillage Related to Field Operations and Soil Management ${ }^{1}$
}

\author{
G. R. BLAKE 2
}

\section{Summary}

Tillage in its broadest sense might include all traffic on the soil required to grow the crop. Thus defined, most tillage is a necessary evil. If one could plant, fertilize, control weeds and insects, and harvest without touching the soil, it might be assumed that the crop would grow just as well. The big question, then, is how to carry out the "indirect" tillage in the simplest possible way, with the least damage to the soil structure, and with the least cost.

Seeding, fertilizer application, thinning, cultivating, harvesting and tillage for special purposes (such as erosion) are usually destructive of the porosity created by plowing. The researcher therefore needs to seek ways to (a) omit unnecessary or least essential tillage, and (b) combine operations so as to reduce the number of trips over a field.

New machines and technology call for a reconsideration of the fundamental notions of soil tillage. Tillage that we assume from instinct to be desirable, that makes the soil "look good", and "reasons" for tillage listed in old textbooks must be seriously questioned and examined. New seed, new fertilizer, new herbicides, new machines and the reservoir of knowledge of basic soil science present the possibility of a revolution in tillage practices.

"Minimum tillage" experiments in the United States of America have aroused great interest among farmers in omitting unnecessary tillage, and in combining a number of tillage practices in the same trip. Yield decreases they were prepared to accept for the greater time-cost efficiency have, in most cases, failed to appear. Improved soil porosity, decrease in weed competition, and great reductions in water runoff and erosion have been additional bonuses. There is reason to believe the results of these experiments might be successfully extrapolated to other soils, crops and climatic conditions.

\section{Introduction}

Previous discussions at this Conference considered the needs of plant roots growing in the soil. Thought was given to what tillage is best and what is necessary to bring about the environment needed by plants. The purpose of this discussion is to consider those auxiliary tillage needs for growing the crop - those indirect tillage operations that are carried out to care for the crop and harvest it.

In this discussion tillage will be used in its very broadest sense to include all operations that affect the soil while growing the crop. This broad definition will include those trips over the soil necessary to prepare a seedbed, apply fertilizer, plant and care for the crop, control weeds, insects and diseases, harvest the crop and dispose of the residues.

1 Paper No. 4978 of the Scientific Journal Series, Minnesota Agricultural Experiment Station.

2 Professor of Soils, University of Minnesota, St. Paul, USA.

Presently on leave as Guest Professor, Institut für Bodenbearbeitung der Forschungsanstalt für Landwirtschaft, Braunschweig-Völkenrode, Germany. 
If one could plant in a well-prepared seedbed, fertilize, control weeds and harvest without touching the soil, we can assume that the crop itself would grow just as well, perhaps better. Much of the indirect tillage is not necessary to improve the physical environment of growing roots. By and large, these operations are indirect, but of course a necessary part of gaining food or fiber from the soil.

The question, then is how to carry out the indirect tillage in the simplest possible way, with the least damage to soil structure, and with the least cost.

\section{The seedbed and seeding}

Soil requirements of seed and growing plants have been considered elsewhere in these discussions. Seedbed preparation will be considered here not from the viewpoint of the need of the crop but from the mechanical aspect of getting the crop started growing.

Plowing provides the opportunity to loosen the soil whose density has increased by the action of water and by contact with men and machines. The exact kind of plowing depends on the crop as well as on the climate. But for row crops in humid climates of the United States, and probably elsewhere, the moldboard plow has not been replaced $(8,16)$. Perhaps improved seedbed preparation equipment can be invented. Adjustments in plow design can certainly improve the quality of the work, as well as reduce the need for further seedbed tillage. The reader is referred to some excellent recently published discussions on the practical aspects of plowing in Europe by experts from six countries (18).

What are the requirements of a seedbed in order to place seed in the soil and get it germinated? Must the soil clods be finely broken up? Most seeds are placed at a depth between 1 and $5 \mathrm{~cm}$. A few centimeters of loose, fairly finely pulverized soil is necessary to insure that the seed will be covered and that it can obtain moisture from the soil.

The requirements for small seeds are obviously different than for large seeds. Potatoes will sprout in soil with a minimum of contact with pulverized soil. If we are to use multi-row planters, the soil surface must be flat and even, especially for small seeds.

It is possible that seedbed requirements for making seeding equipment useable are not the requirements of the growing plant at all? Perhaps consideration should be given to the point of view that the soil requirements for sowing are one thing and the soil requirements for seed germination and growth are something else. The conclusion might then be reached that getting the seed into the soil is a cost against a good soil environment for the plant. Perhaps heterogeneity in a seedbed is more desirable than homogeneity. Pulverizing the soil to a depth of more than about $6 \mathrm{~cm}$ is not necessary to get the seed in the soil. Nor is pulverization necessary for more than a few centimeters horizontally around the seed. Yet traditionally a seedbed is made on the whole soil surface even when planting in rows $100 \mathrm{~cm}$ apart. LARSON has recently discussed some of the basic considerations of seedbeds for maize (13).

\section{Fertilizing}

Adding fertilizer to the soil, either as chemicals with high percentages of nitrogen, phosphorus, and potassium, or as manure to which these are added, may require 
some degree of mixing with the soil. Often this mixing is combined with other tillage. Thus manure or chemical fertilizer is plowed in. There are still the questions, however, of how thorough to mix. Should fertilizer be banded, or thoroughly mixed; should it be added one or more times per year; should it be added in the spring, fall, winter or summer? Can it be added at the same time other tillage is done, for example at the time of seeding? Obviously it is impossible to generalize, because the answers to these questions depend on the crop, the soil, the climate and perhaps on whether the fertilizer is principally organic or inorganic. As a guideline, it seems important to disturb the soil as little as possible consistent with getting fertilizer where it can do most for the crop.

It is obvious that in our research on these problems, as in all our research on the complicated soil-crop system, we must seek to group crops, climates and soil types and thereby make intelligent recommendations to farmers.

\section{Cultivating and thinning}

Seedbeds are often prepared in such a way as to facilitate weed hoeing during the season. It is assumed that a pulverized seedbed is necessary so that cultivation does not uproot small plants near the soil surface, nor disturb them by moving submerged clods. Also a course seedbed is difficult to cultivate without throwing large clods on the small seedlings. Have we lost sight of the fact that weeds germinate and grow better on a pulverized smoothed seedbed? Is it possible that if the soil between rows of small seeds were rough, there would be less need to cultivate, and also that the need for cultivation would be delayed one to three weeks until seedlings were better established?

It is well established that one cannot hope to germinate all weeds and thereby destroy them. Our tillage system should rather be aimed at preventing their germination. Now that engineers can make machines for almost any specific purpose, and further, that there is ample power to drive them, we should think in terms of tilling where only the crop can benefit.

\section{Weed and insect control}

Have tillage practices been integrated with herbicides? There are now a host of chemicals for supplementing tillage. Band spraying at planting time lessens the weed problem near crop plants. Is it possible that by leaving the soil loose, rough and cloddy between crop rows, spraying with a herbicide to delay weeds in the crop row, a great deal of summer cultivation can be eliminated? Perhaps all cultivation could be eliminated in some crops.

Aside from their practical use in farming, herbicides offer the researcher a tool for applying variable cultivation on field plots. Their development opens up opportunities for modifications of our tillage practices that may have far-reaching consequences.

Some tillage operations are associated with insect and plant disease control. Incorporation of residues to control wheat scab, cabbage clubroat, pea root rot, tillage to encourage soil microflora that controls potato scab, or cotton root rot are only a few examples. These examples point up the necessity to consider both the microplant population as well as higher plants in our tillage practices. 


\section{Harvesting}

Farmers sometimes till the soil for the purpose of making harvesting easier. Perhaps this is the principal reason for ridging potatoes. Other reasons are cited for ridging such as aeration and for drainage, preventing the greening of tubers, and others. But do we know, or do we just suppose, these are the reasons? Perhaps the only valid reason for ridging is to make it easy to get a mechanical blade underneath the potato tubers in harvesting and to greatly reduce the power required to do it.

It does not appear to be necessary to pack soil in order to improve traction or trafficability. It is true that pulling harvesters in loose soil requires more power. But with modern tractors this is not a great difficulty. It is doubtful that limited power for harvesting can be a valid excuse for packing soil beforehand.

\section{Special tillage requirements}

In some areas of the world special tillage practices demand priority. This is true in areas where soil erosion hazard is high.

One of the best examples of specific tillage requirements is in the sub-humid "wheat belts". The specific conditions that dictate special tillage for these soils are found in the Plains States of Canada and the United States. Perhaps similar climatic conditions exist also in parts of southeastern Europe, the middle east and southern U.S.S.R. Climates are typically continental. Rainfall is sparse, ranging from 30 to $45 \mathrm{~cm}$ per year. In the American Plains the rains are likely to be extremely intense, 6 to $8 \mathrm{~cm}$ in a single day being not uncommon. Soils in a virgin state are brown and fertile. Winds of high evaporative potential are usual. Between rains the soil becomes dry and is subject to erosion by wind. Tillage for erosion control includes leaving residues at the surface, and leaving the soil surface rough and cloddy. Wind velocities at the soil surface are thus reduced and erosion by wind is minimized. The rough soil surface also forms numerous small catchment areas to hold intense rains until it can infiltrate the soil, thus reducing the hazard of soil loss by surface runoff. Most other tillage practices in these areas are dictated by the need to control erosion.

A second typical situation is where all tillage adjusts to the need for water erosion control. This is found in the hill lands where there is also high rainfall. These areas occur here and there on every continent. The southeastern United States are typical. Annual rainfall of 100 to $150 \mathrm{~cm}$ on 10 to $18 \%$ slopes can result in serious erosion. All tillage adjusts to the need for infiltrating as much water as possible and conveying the excess safely into drainageways. Contour planting, strip cropping, terracing, grassed waterways and other control measures are of highest priority in any system of tillage on these soils. Most of our farmlands in central Europe and central United States of America have an intermediate erosion hazard. Reasonable changes in tillage do not endanger erosion control. It is in these intermediate areas that we have the greatest flexibility in trying new tillage schemes and practices.

\section{Overall view of tillage}

It is obvious that tillage operations, other than plowing, rototilling or deep cultivation of dry soils, do not loosen the soil below the surface few centimeters. Most operations increase the bulk density. If soils are to retain the loosening effects of 
plowing, then the need for all other tillage must be carefully scrutinized and questioned by the researcher. Is there value in plowing to loosen soil only to re-pack it to the same bulk density it had before plowing?

Many practices developed and used by farmers for centuries are based on sound reasons. But all too often tillage is carried out because we have a notion it should be good. Appearance to the eye is perhaps too often a criteria for tillage! There must be a reconsideration of our fundamental notions, a reconsideration that is based on research evidence rather than on instinct and intuition.

Seriously consider why various tillage operations are used. Reasons are given in books and pamphlets for every tillage operation. The objectives of tillage given in textbooks are reasonable. They sound logical and true. But unless they are based on sound research it is possible that they may not be true at all. If a farmer is asked why he performs a certain tillage operation, he can give reasons. But scientists must question, and to themselves doubt, his reasons. He must then test. And perhaps he will indeed find the tillage operation to be beneficial, but for a wholly different set of reasons than were cited. It is only in this way that scientists can take up the challenge to find a "concept of soil tillage" laid down by Prof. Frese in his talk to the International Society of Soil Science two years ago (9).

In a search of the literature by the writer no experiment was found whose aim was to determine whether flat cultivation of potatoes resulted in increased "greening" or "scalding" of exposed tubers. In sandy soils in New Jersey, in one year, potatoes were grown with and without ridging. No evidence was found that ridging reduced the percentage of exposed tubers ${ }^{3}$. Perhaps such data are somewhere available, but there is doubt that this "reason" for hilling potatoes is a valid one on all soils.

Scientists must not be content with unproven reasons. They must ask the questions of every tillage operation: "Is it necessary?" and "Would the crop grow as well, or perhaps even better without it?"

\section{Soil compaction}

Much is written and spoken, and there is worry, about soil compaction. Anxieties are intensified by the increasing size and weight of farm machinery.

Soil compaction refers, of course, to increasing of soil bulk density. Soils have the lowest density immediately after plowing. Bulk density increases principally in two ways: By the action of water upon soil crumbs, and by the action of men or animals and their machines.

The action of rain on bulk density depends on the amount and intensity, or distribution, of precipation. But the ability of soils to resist breakdown of soil crumbs varies greatly, depending principally on soil texture, but also upon the strength of inorganic-organic bonds. There are a number of known practices that reduce breakdown of crumbs under a given rainfall amount and intensity. Cover crops, organic mulches, manipulating the crop canopy to maximize soil cover are but a few of these practices.

As has been pointed out, it must be assumed that essentially all tillage other than plowing increases the soil bulk density. It is these practices the researcher should look at, to ask again — is this practice or that tillage essential? He must weigh

3 Unpublished data of the author. 
the known value (the known value, not the supposed value) of a tillage operation against its destructive effect on soil pore space.

We have not done as well in avoiding soil structure breakdown or compaction by machines as we have in avoiding it by the action of water. The alarming proportions of this "traffic" are illustrated by an estimate that on some New Jersey, USA, potato farms, tractors travel as far as $80 \mathrm{~km}$ per hectar per year (20.4 miles per acre) to grow the crop ${ }^{4}$. Not only does this "traffic" reduce yields, it is a direct cost to the farmer in labor and equipment.

Deliberate packing of Bearden silt loam surface in Minnesota, USA, resulted in yield reductions over a two year period of 13 and $9 \%$ for sugar beets and wheat, and $54 \%$ for potatoes (1). In addition, potato tubers were of lower specific gravity and set nearer the soil surface (3), and the percentage of sprangled sugar beets doubled on packed soil (5). Packing Waukegan silt loam in the surface $(0-20 \mathrm{~cm})$, or subsurface $(20-50 \mathrm{~cm})$ reduced maize yields $7.5 \%$ and $3.2 \%$ respectively; packing both layers, $14.5 \%$. Effect of packing was independent of fertilizer level (1).

\section{New tillage concepts and practices}

What can be done to avoid soil structure damage, i.e. specifically compaction, by machines? Since farmers are not likely to do away with the machines, other approaches must be sought. There are at least two: One is to omit the least essential tillage operations; two, combine tillage operations to reduce the number of trips. It is in these two directions that experiments have been carried out in the United States of America over the past 10 years with rather remarkable results.

Early researchers had established that controlling weeds by hand hoeing or cutting gave just as good maize yields as control by cultivation (6). There was always the question of whether the hand hoeing had not been, in effect, a cultivation. With the advent of herbicides experiments were possible in which stirring with a hand hoe could be eliminated. One cultivation was found desirable for maize, but more than one did not appreciably increase yields $(2,19)$. It was found that the usual 5 to 7 cultivations for potatoes in New Jersey sandy loam to loamy sand soils could be reduced to 1 or 2 with a yield gain in some years provided weeds were controlled (see FIGURE 1). Experiments on Bearden silty clay loam, a calcium carbonate Solonchak with an organic matter content approximately $6 \%$, confirm this result for potatoes (4).

Many other experiments at various locations in the United States of America have been carried out to find ways to reduce the amount of seedbed preparation and cultivation. Methods of achieving seeding on rough seedbeds as well as use of technological achievements in machinery and herbicides have been combined, with the result that far less tillage is necessary. These have collectively been referred to as "minimum tillage" practices. There are, of course, many variations of minimum tillage. Two of the best known of these are "wheel track planting", and "plow planting". Wheel track planting consists of planting in the soil firmed by the tractor wheels of the tractor used to pull the planter. There is often no other seedbed preparation than plowing itself. Tractor wheels are adjusted to the usual 1 meter (40 inch) row width for maize. The only tracks left on the plowed soil are the tractor tracks and the planter wheels following in the same tracks.

4 Unpublished author's data. 


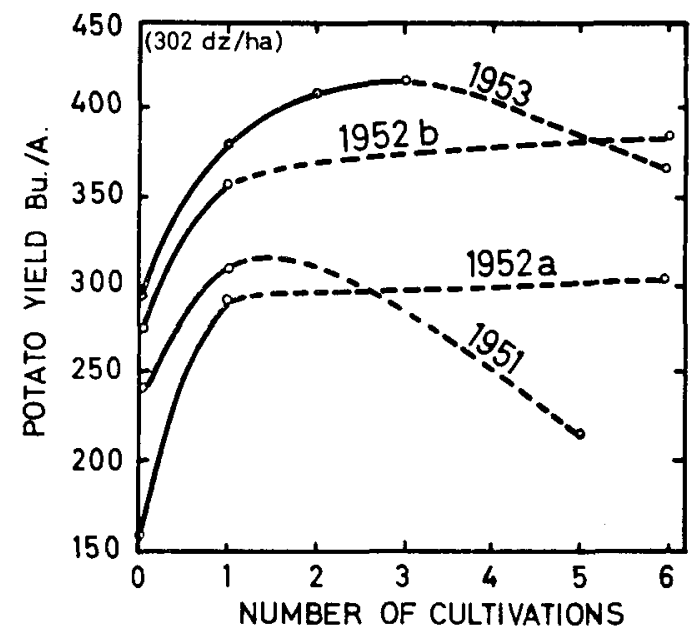

Fig. 1.

Effect of numbers of cultivations on potato yields on sandy loam and loamy sand soils in New Jersey, USA (2). Data from $1952 \mathrm{a}$ and $1952 \mathrm{~b}$ refer to experiments on two soil types

The tractor wheels break up clods and firm the soil where the seed is placed. An herbicide is sprayed over the row in a band about $20-25 \mathrm{~cm}$ wide, and fertilizer is placed in a band alongside the seed at the time of planting. Thus two trips one for plowing, one for planting, fertilizing and spraying weed chemicals - prepare the seedbed and plant the crop. The 70 to $80 \mathrm{~cm}$ space between the planted rows remains loose and rough as it is after plowing.

Great advantages result from this system of maize planting:

Time and cost of tillage are reduced. Loose soil in the spaces between the rows is highly permeable to air and water thereby greatly reducing soil and water loss from intense rains. Weeds grow poorly in the inter-row spaces where the soil is not firmed. Thus, with herbicides covering the row, cultivation need is reduced.

Cultivation of weeds in a course seedbed is not a problem, because cultivation is delayed until maize is 40 to $60 \mathrm{~cm}$ high. At that age, plants are not easily damaged by rolling clods. Furthermore, since weeds are controlled near the plants, close cultivation is unnecessary.

Wheel track planting is successful on soils of all textures. On sandy soils, where spring plowing is usually preferred, planting is done immediately behind the plow. Planting in moist sand provides for both moisture and moderated surface temperatures, conditions that are ideal for seed germination. On fine textured, relatively flat soils where fall plowing is usually preferred, it is sometimes necessary to till the soil before planting to kill germinated weeds. This tillage can be accomplished by using a tractor-mounted cultivator to pull the planter. It is often done, in practice, by pre-planting cultivation as a separate tillage operation. Use of a disc harrow for this purpose is discouraged because it packs the soil and thus counteracts the minimum tillage advantages.

Many farmers have devised ingenious ways of modifying tractor wheel widths to accomodate the one meter row-width for maize. Most midwestern farmers now prefer to plant and cultivate four rows at a pass, and many variations in tractor and planter modifications have been designed. Some modifications are commercially available.

Plow-planting goes one step further than wheel track planting. In this method, the 
FIg. 2. Combining seedbed preparation, fertilizing, planting, herbicide and insecticide applications for maize in one trip.

(Photo courtesy Webb Publishing Co., St. Paul, Minnesota, USA)

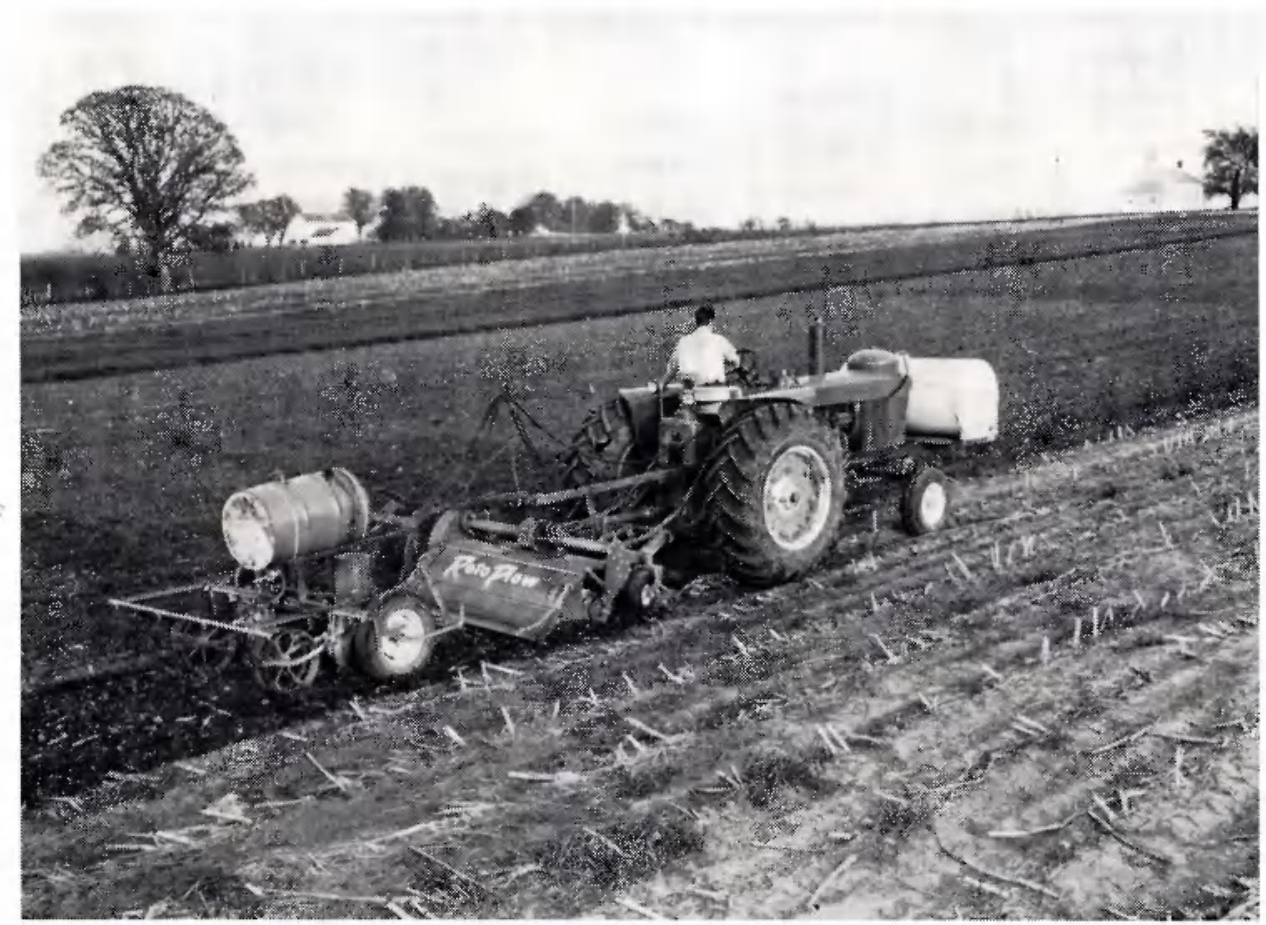


seedbed is prepared and planted in one operation. MusGrave and coworkers (14) have experimented with a one row planter mounted on a 3 bottom plow that plows a 1 meter strip; they have also used a 2 row planter mounted on a 5 bottom plow that plows a 2 meter strip.

Farmers themselves, as well as machinery manufacturers, are designing and experimenting with machines that combine a number of operations. One such machine, made and used by Mr. Schiltz, a Minnesota (USA) farmer is shown in FIGURe 2 (7). In one pass the seedbed is prepared, two rows of maize are planted, fertilized with a liquid fertilizer, and an herbicide and an insecticide are applied. Each of $\mathrm{Mr}$. Schiltz' two machines covers 0.8 ha (2 acres) an hour. In 1961 and 1962 only part of the maize fields required cultivation for weeds. Part was not cultivated. In 1961 his yields averaged $65 \mathrm{dz} / \mathrm{ha}(97 \mathrm{Bu} / \mathrm{A})$ maize grain on 92 hectares (227 acres), and $27 \mathrm{dz} / \mathrm{ha}(40 \mathrm{Bu} / \mathrm{A})$ on 40 hectares (100 acres) soybeans. Labor efficiency on this farm is shown by the fact that the farmer, his father and a hired laborer farm a total of 610 ha (1507 acres), half of which is tillable. They milk 75 cows and keep 85 head of young stock.

It is not alone prevention of compaction that has promoted the tremendous interest in minimum tillage; it is also increase in efficiency. In the United States of America where soil resources are abundant and not fully developed, it is output per man hour that is often decisive rather than output per acre. Farmers were willing to accept reduced yields per acre if tillage costs and labor input could also be reduced. Reduced yields, however, have not proved necessary under "minimum tillage". On the contrary, experiments in a number of states have shown that yields are not greatly affected, but are often a little greater under "minimum" than under "conventional" tillage practices. In 49 single plot comparisons in Minnesota in 1956 and 1957, maize yields averaged $3 \%$ higher with wheel track planting and minimum tillage than with conventional tillage (15). Results given in TABLE 1 from a replicated experiment in Minnesota are typical of those found in experiments in several states.

TABle 1. Maize yields as related to seedbed tillage (Unpublished data, Minnesota, USA)

\begin{tabular}{llc}
\hline Seedbed tillage & When Plowed & $\begin{array}{c}\text { Relative yield } \\
1958-1961\end{array}$ \\
\hline Minimum $\ldots \ldots \ldots \ldots \ldots \ldots$ & Spring & 100.0 \\
Minimum $\ldots \ldots \ldots \ldots \ldots \ldots$ & Fall & 102.6 \\
Conventional $\ldots \ldots \ldots \ldots \ldots$ & Fall $\ldots 5.9$ \\
Field cultivate $\ldots \ldots \ldots \ldots$ & Fall + Spring & 94.3
\end{tabular}

Yield differences significant only in 1958 when fall plowing was superior to spring.

Tillage for maize in the middle western United States has been revolutionized. Many farmers are wheel track planting or are plow-planting, though the percentage of land thus tilled is still not great. Nevertheless, the vast majority of farmers have reduced their pre-planting tillage to one half or one third that previously used. Farmers themselves are in a race to see how few hours they must apply per acre and still maintain their high yields. Some farmers boast they can grow a hectar of maize grain with a total time input on the land of 2.5 to 3.0 hours from seedbed preparation through harvesting. 
Researchers in the United States are not sure how far their results can be extrapolated to other soil types, climatic conditions and crops. There have, however, been suggestions that minimum tillage principles apply to citrus in Australia (11) and California, USA (10), plums in Palestine (17) and lettuce in California (20). A remarkable series of experiments with sugar beets, potatoes and kale on two soil types in England has been summarized by KEEN (12) as follows:

"The net result of all this work is to show that provided the crop has a reasonably fair seedbed, that it is given a hoeing in its early stages, and that the worst of the later weeds are kept down, then any cultivation of the soil - whether before sowing or during growth - in excess of this minimum is of little direct value to the plant". KEEN further explains that the early cultivation is only for the purpose of controlling weeds. He concluded that plants are remarkably insensitive to the seedbed. The large number of experiments with maize, soybeans and potatoes in the United States are a strong confirmation of the principles found in the early British experiments.

Perhaps the revolution in tillage practices has only begun. Modern machinery in a modern highly organized society provides the means to experiment with fantastic tillage treatments. Conventional and traditional ways and practices of tillage are being challenged. Thereby the researcher is challenged. The results of continuing experiments lead him to believe that further advantages can be gained by continued evolution in tillage practices.

\section{I T E R A T URE}

1. Adams, E. P., G. R. Blake, Influences of soil compaction on crop growth and developW. P. MARTIN and ment. Trans. Seventh Int. Congr. Soil Sci. 1: 1607. 1960.

D. H. Boelter

2. BLAKE, G. R., and R. J. Aldrich

Effects of cultivation on some soil physical properties and on potato and corn yields. Soil Sci. Soc. Am. proc. 19: $400,1955$.

3. Blake, G. R., D. H. Boel- Soil compaction and potato growth. Am. Pot. Jour. 37 : TER, E. P. ADAMS and 409. 1960.

J. K. AASE

4. Blake, G. R., G. W. French and R. E. NYLUND

5. Blake, G. R., D. B. OGDEN, Effect of soil compaction on development and yield of sugar E. P. Adams and D. H. BoElTER

Seedbed and cultivation studies with potatoes. Am. Pot. Jour. 39 : 227.1962.

6. Cates, J. S. and H. R. Cox The weed factor in the cultivation of corn. U.S. Dept. Agr.

7. Doughty, ToM

8. Feuerlein, W.

9. Frese, H.

10. Johnston, J. C., and W. Sullivan

11. KeBBY, R. G., and A. H. SHEPPER
Bul. 257. 1912.

Here's one-operation corn growing. The Farmer (Minnesota, USA), p. 11, June 2, 1962.

Kann der Pflug ersetzt werden? Landw. Wochenschau, Westf.Lippe, Folge 19, S. 1029. Mai 1959.

Haben wir ein Konzept für eine Wissenschaft von der Bodenbearbeitung? 7th Int. Congr. Soil Sci. Gen. 6, Vol. I, p. 54-66. 1960.

Eliminating tillage in citrus soil management. Calif. Ext. Serv. Circ. 150. 1949. (Soils and Fertilizers 12: 1880).

Citrus fruit quality, what are the main considerations? N.S.W. Agric. Gaz. 59 : 357. 1948. (Soils and Fertilizers 12 : 265). 
12. KeEN, B. A.

13. Larson, W. E.

14. Musgrave, R. G., P. J. ZWERMAN and

S. R. AldRICH

15. Overdahl, C. J., G. R. Blake, C. A. VAN DOREN and R. F. HolT

16. Page, J. B., C. J. Willard and G. W. MCCUEN

17. SAMISCH, R. M.

18. Symposium

19. Swanson, C. L. W., and H. G. M. JACOBSON

20. VEIHMEYER, F. J., and A. H. Holland
Physical research on problems of soil cultivation. Endeavour 1: 52. 1942. See also B. A. KEEN. Soil Physics: Theory and Practice, Lecture 3 Cultivation and Crop Yields. J. Roy. Soc. Arts. 90 : 569. 1942.

Tillage Requirements for Corn. J. Soil and Water Conservation. 17 : 3. 1962.

Plow-planting of corn. Agr. Eng. (Mich.). 36: 593. 1955.

Where do we stand on minimum tillage. Minnesota Farm and Home Science. 16: 14. 1959.

Progress report on tillage methods in preparing land for corn. Soil Sci. Soc. Am. Proc. 11: 77. 1947.

Plum growing in the Jewish settlements of Palestine. Ag. Res. Sta. Rehovat, Bull. 50. 1949. (Soils and Fertilizers 12: 326).

Der Pflug in internationaler Sicht. Contributors: K. GRAF, W. FEUERLEIN, V. OLSON, A. NJÖS, G. TORSTENSSON, E. R. FOUNTAINE, W. CZERATZKI, H. KUIPERS and H. FRESE. Mitt. d. Deutschen Landw. Ges. Heft 13. 1959.

Effect of adequate nutrient supply on soil structure and corn yields. Agron. Jour. 49 : 571. 1957.

Irrigation and cultivation of lettuce. Calif. Ag. Expt. Sta. Bull. 711. 1949. (Soils and Fertilizers 12: 1904). 